\title{
Digital services of Libraries in the Era of Mobile Internet
}

\author{
Yanxiang LU \\ The Library of Jianghan University, Wuhan, 430056, China \\ email: 327579500@qq.com
}

Keywords: Mobile Internet; Library; Digital services

\begin{abstract}
The full coverage of the network, cloud digital products and the ever-upgrading reading devices have transformed users' reading environment, reading content and reading mode in a profound way. Against the backdrop of Information Era, Libraries are supposed to keep up with the times, with a bid of catering to demands of readers, by means of making full usage of the Internet and information technology, providing user-centered, tailor-made services.
\end{abstract}

\section{Introduction}

The booming of Mobile Internet, digital products growing rapidly and diversity of reading modes have transformed the service mode of library. In order to adapt the change, libraries start to contribute application of the discovery System, provide personalized service based on big data of user information, promote mobile library and provide pervasive service.

\section{The Development of Information Technology Induced the Digital Reading Environment}

According to the latest report from China Internet Network Information Center (CNNIC), as of December 2014, the number of Internet users in China has reached 649 million, the Internet penetration rate is $47.9 \%$, and the mobile Internet users are as many as 557 million. Moreover, the rate of Internet users via mobile phones is $85.8 \%$, in comparison to $81.0 \%$ in 2013 . Tablets become the primary mobile devices for the recreational and convenient features, resulting in an even higher utilization rate in highly-educated high-income earners [1]. The third wave of the Internet is the "mobile Internet", which transformed users' reading mode, lifestyle and mindset significantly. The mobile Internet is making information more accessible and pervasive.

In 2012, the Encyclopedia Britannica announced that it would put an end to the printed version and publish digitally. New forms of digital publication continue to emerge, including e-books, digital newspapers, digital journals, cyber literature, network maps, digital music, mobile publications. Digital publishing in the Internet Age has reshaped the mode of information dissemination, and has in turn profoundly affected readers' reading habits and mindset. Generally speaking, the annual input of libraries into digital resources has been increasing year by year.

According to a report released by the Twelfth National Reading Survey, 58.1\% of adult readers in China have adopted digital reading somehow in 2014(including online reading, mobile reading, kindle reading, disc reading, tablet reading). Online reading, mobile reading and disc reading have seen an obvious increase the same year. In 2014, 49.4\% of adults read online, with an average daily exposure to the Internet as long as 54.87 minutes. 51.8\% of adults read via mobile phones, with an average reading time of 33.82 minutes per day. The WeChat reading rate among adults is as high as $34.4 \%$ in $2014[2]$.

In short, the revolution of digital reading fueled by innovated information technology has cultivated readers' digital reading habits in one way or another.

\section{Reading Attributes of the Mobile Internet Era}

With the popularity of the Internet and smart-phones, online reading and mobile reading are becoming increasingly pervasive. As a primary way of acquiring knowledge and information at 
present, digital reading has gradually gone mainstream.

The quick pace of modern life requires people to obtain massive information in a short period of time with high efficiency. Fragmented reading is coinciding with the fragmentation of time. After the birth of e-reading, service providers have adopted focus strategy in the face of the mass of reading contents, which therefore leads to the fragmentation of reading contents. Alvin Toffler, the famous futurologist in the U. S., noted in his book of The Third Wave : This is a fragmented era, along with fragmented data and a fragmented audience.

There is little doubt that the multimedia-based "screen browsing " and "picture reading" make information acquisition far more efficient and intuitive than ever, which takes an increasing portion of everyday reading. Digital reading has therefore refreshed readers' experience. The massive information gives rise to the skimming habit, while the fragmented time brings about micro-reading.

\section{Digital service of Library}

Although readers have access to the massive information from the Internet, due to the lack of an effective filtering mechanism, readers need to spend a great deal of time filtering the information. In spite of the fact that the new media is far more accessible, interactive, timely, the fragmented reading is not conducive to the construction of a rational, systematic knowledge structure.

In the Information Era, the construction of digital resources collection in libraries has been developing by leaps and bounds. All kinds of introduced or self-built databases become an important part of the collection of library resources. But it' s time-consuming for users to learn about how to make use of different databases, they also need to shift from one database to another for completing a cross-database search. Accustomed to using such efficient and user-friendly search engines as Google or Baidu, users require the library to provide a similar unified search engine applicable for all the resources of the library.

The Unified Resources Discovery System came into existence under such circumstances, which can carry out a single search covering resources across heterogeneous platforms via a unified search portal. This searching system integrates paper and electronic resources of the library, provides the original links and facilitates easy access at the same time. At present, the employment of Discovery Systems like the Primo, EDS, Local Summon and Encore are quite common in university libraries. Peking University Library, Beijing Normal University Library and Zhejiang University Library have introduced the Summon system, while Tsinghua University Library, Shanghai Jiao Tong University Library have chosen the Primo system.

Mining and Classification. User behavior in the process of information retrieval and utilization is the explicit indication of the user' s searching target or query intention. Libraries collect big data by tracking users' browsing behavior (browsing features, attention distribution, etc.), download patterns (time distribution, spatial distribution, downloaded content, degree of association), links (focus of attention, circle of friends, social network, agglomeration and so on) and interactive behavior (focus of attention, comment, retweeting, sharing, online Q \& A, etc.). Through data mining of the structured, semi-structured and unstructured information concerning user behavior, libraries are enabled to provide more personalized services [4].

Communication and Interaction. According to the survey of 2012 IFLA Metropolitan Library Committee, three quarters of libraries are making use of social media in services, among which 89\% of libraries are using Facebook, $80 \%$ of libraries are employing Twitter, while $76 \%$ of libraries are utilizing Blog to provide information service. These social media tools are making communication more effective between libraries and readers. What's more, Librarians can conduct conventional reference services on a professional digital reference platform, with the aid of QQ, WeChat at the same time [5].

Sharing and Push Service. At present, the OPAC system in most libraries has been integrated with bibliographic data and online information. Taking advantage of the X-OPAC system, Jianghan University Library has enriched bibliographic data by including the book cover, contents, reviews 
from Douban, sharing in MicroBlog. Users are able to create a digital personal bookshelf, write book reviews online. Nanjing University Library promotes a mobile service named Mobi+: on a regular basis, it pushes the latest information resources to readers according to their personal demands.

With the rapid development of mobile network technology and mobile hardware innovation, the network is shifting from a static mode to a dynamic pattern. The Mobile library is on the highway of development in China. According to statistics, 67\% of “Project 211 ” university libraries provide mobile information services. Currently, Mobile Library Service takes form of 5 main modes: SMS service mode, MMS service mode, Web service mode, APP service mode and WeChat service mode. The mobile services feature in promptness, interactivity and personalization[6].

Promptness: Libraries provide the service of resources / bibliographic query, borrow history saving, book renewal /reserve, full-text download, SMS reminder (the latest booklist, to reserve or renew books) .

Interactivity: Libraries provide the service of evernotes, book reviews, literature annotations, bookmarks, document downloads, document sharing, bestseller recommendation, journal navigation, book purchase suggestion.

Personalization: Libraries provide the service of borrow management, personal favourites, RSS management, mobile phone binding, searching history, recently-visited websites.

With the popularity of smart-phones and upgrading of the wi-fi network, mobile reading has become increasingly pervasive. Readers are able to utilize the digital resources of a library at any time, in any place.

\section{Conclusion}

In the Age of Big Data, libraries strive to make full use of the mobile Internet providing tailor-made digital services based on in-depth data mining and analysis. Nowadays, quality information resources and services provided by libraries have made an appearance on the interfaces of Iphone, Ipad, Samsung, Blackberry and other cutting-edge digital products, facilitating the utilization of fragmented time to experience the systematic learning process,contributing enormously to the consistent lifelong learning notion.

\section{Acknowledgment}

In this paper, the research was sponsored by the Humanities and social sciences research and guidance project of Hubei Provincial Education Department(Project No. 15G079).

\section{References}

[1] CNNIC released the thirty-fifth China Internet development statistics report. [EB/OL]. http://www.cnnic.net.cn/gywm/xwzx/rdxw/2015/201502/t20150203_51631.htm. [2015-02-03].

[2] Twelfth National Reading survey data released in Beijing. [EB/OL]. http://www.chuban.cc/yw/201504/t20150420_165698.html [2015-04-20].

[3] Shen Si. An Overview of Mobile E-Library Development at Home and Abroad [J]. Information Documentation Service, 2013(6) 31-34.

[4] Yu shiying, Ming junren. Analysis of the Application on Model of Mobil Information Services in Domestic Academic Libraries [J]. Document, Information \& Knowledge, 2012(6)60-67.

[5] Rane, Manisha Yogesh. Digital Libraries: Practical Approach [J]. International Journal of Multidisciplinary Approach \& Studies, 2015:2 (1)142-150.

[6] Liu yanquan, Briggs, Sarah. A Library in the Palm of Your Hand: Mobile Services in Top 100 University Libraries [J]. Information Technology \& Libraries, 2015: 34(2)133-148. 